\title{
PERANCANGAN SISTEM INFORMASI AKADEMIK BERBASIS WEB PADA SEKOLAH ISLAM MODERN AMANAH
}

\author{
Dewi Maharani \\ Manajemen Informatika, Amik Royal Kisaran \\ Jl. Imam Bonjol No.179 Kisaran, Telp: 0623-42451, Faksimili: 0623-42366 \\ e-mail : dewimaharani15@gmail.com
}

\begin{abstract}
Abstrak
Tujuan penelitian ini untuk merancang sistem informasi akademik berbasis website sekolah Islam Modern Amanah Medan. Metodologi yang digunakan dalam perancangan sistem informasi ini menggunakan Content Management System Schoolhost yang memang khusus diperuntukan untuk sekolah. Hasil penelitian ini menunjukkan bahwa penggunaan sistem informasi berbasis website dapat menjadi sebuah Revolusi Publikasi dalam membuka jangkauan informasi sekolah yang lebih luas lagi untuk menyampaikan berbagai jenis informasi mengenai sekolah tersebut, memberikan kemudahan dalam aktivitas-aktivitas akademik menghilangkan batasan waktu, jarak dan tempat sebagai penghambat untuk para siswa/i, orangtua, serta masyarakat yang ingin mencari informasi tentang sekolah yang bersangkutan.
\end{abstract}

\section{Kata Kunci: Sistem Informasi, Sistem Informasi Akademik, Website Sekolah}

\section{PENDAHULUAN}

Dunia pendidikan saat ini berkembang dengan begitu pesatnya. Perkembangan pesat ini, seiring dengan berkembangnnya teknologi dan informasi yang sedang terjadi. Teknologi informasi yang beraneka ragam, memerlukan peningkatan mutu dan mekanisme pelayanan di bidang pendidikan agar lebih berdaya guna, sehingga Sumber Daya Manusia (SDM) yang telah di hasilkan dari dunia pendidikan dapat memberikan kontribusi dalam membangun dunia luar sesuai dengan keahliannya. Banyak cara yang dapat di lakukan untuk mendapatkan dan mengetahui perkembangan teknologi yang sedang terjadi. Salah satunya adalah dengan memanfaatkan komputer sebagai sarana untuk mengakses jaringan internet.

Dengan perkembangan teknologi informasi pada saat ini, guru dapat memberikan layanan tanpa harus berhadapan langsung dengan siswa. Demikian pula siswa dapat memperoleh informasi dalam ruang lingkup yang lebih luas dari berbagai sumber melalui menggunakan internet. Pembelajaran maya, yaitu proses pembelajaran yang dilakukan dengan menggunakan internet. Biasa disebut dengan E-Learning. e-learning yaitu model pembelajaran dengan menggunakan media teknologi informasi dan komunikasi khususnya internet.

Sekolah Islam Modern Amanah, yang memiliki tingkat SD dan SMP ini memiliki tujuan yang sangat mulia, yaitu untuk membantu pemerintah dalam mencerdaskan bangsa melalui usulan penyediaan sarana pendidikan guna meningkatkan Sumber Daya Manusia yang Berakhlatul Kharimah dan berkarakter. Pada dasarnya Sekolah Islam Modern Amanah belum mempunyai sistem informasi berbasis web, yang mengakibatkan proses penyampaian informasi tidak berjalan dengan maksimal untuk kalangan pelajar dan kurangnya komunikasi di luar akademik antar guru dengan murid. Melihat Ketidak adanya sistem informasi akademik yang berbasis web, serta perkembangan teknologi informasi yang sangat penting untuk kemajuan sekolah dan besarnya manfaat yang diperoleh, peneliti membuat sebuah perancangan dalam hal sistem informasi akademik.

\subsection{Rumusan Masalah}

Berdasarkan uraian latar belakang masalah yang telah penulis buat, maka penulis merumuskan masalah atau kendala yang dihadapin Sekolah Islam Modern Amanah agar tidak menyimpang dari judul yang di berikan, yaitu: Bagaimana menyediakan informasi akademik secara online tentang Sekolah Islam Modern Amanah, sehingga masyarakat dapat mengakses informasi yang ada dengan cepat dan tepat melalui internet.

\subsection{Tujuan Penelitian}

Adapun tujuan dari penelitian ini adalah:

1. Sebagai sarana pembelajaran bagi siswa-siswi, dan seluruh civitas akademik.

2. Sebagai salah satu sarana informasi

3. Agar para Bapak dan Ibu Guru beserta Staff Sekolah dapat saling berinteraksi dan berkomunikasi lewat web akademik

\subsection{Batasan Masalah}

Adapun yang menjadi batasan masalah dalam penelitian ini adalah sebagai berikut:

a. Sistem informasi berbasis web ini dipergunakan hanya untuk kepentingan penyampaian data dan informasi kepada penggunanya. 
b. Adapun yang akan disampaikan dalam sistem informasi berbasis web ini antara lain:

1. Menampilkan informasi tentang sekolah islam modern amanah.

2. Menampilkan data para guru, siswa, mata pelajaran yang ada pada sekolah islam modern amanah dan hal yang terkait dengan akademik lainnya.

\subsection{Manfaat Penelitian}

Manfaat penelitian adalah sebagai berikut:

a) Manfaat Terhadap Dunia Akademik

Hasil penelitian ini diharapkan dapat meningkatkan citra baik sekolah, sebagai media Promosi kepada masyarakat secara online dan para guru akan lebih mudah melakukan pemberian, pembaharuan materi maupun model pengajaran sesuai dengan tuntutan perkembangan keilmuan yang terjadi, juga dapat dengan efisien mengontrol kegiatan belajar siswanya.

b) Manfaat Terhadap Dunia Praktis

Sebagai bahan referensi untuk menangani masalah-masalah yang berhubungan dengan sistem informasi akademik khususnya website.

\section{LANDASAN TEORI}

\subsection{Website}

Situs web (bahasa Inggris: web site) atau sering disingkat dengan istilah situs adalah sejumlah halaman web yang memiliki topik saling terkait, terkadang disertai pula dengan berkas-berkas gambar, video, atau jenis-jenis berkas lainnya. Aplikasi web adalah aplikasi yang disimpan dan dieksekusi dilingkungan web server. Setiap permintaan yang dilakukan oleh user melalui aplikasi klien (web browser) akan direspon oleh aplikasi web dan hasilnya akan dikembalikan lagi ke hadapan user. Dengan aplikasi web, halaman yang tampil di layar web” (Raharjo, 2010)

\subsection{Domain}

Menurut wikipedia, nama domain berarti "nama unik yang diberikan untuk mengidentifikasi nama server komputer seperti web server atau email server di jaringan komputer ataupun internet."

\subsection{Web Hosting}

Web Hosting adalah salah satu bentuk layanan jasa penyewaan tempat di Internet yang memungkinkan perorangan ataupun organisasi menampilkan layanan jasa atau produknya di web / situs Internet. (http://id.wikipedia.org/wiki/Webhosting, 2013).

\section{$1.4 \quad$ Internet}

Internet adalah singkatan dari International Network yang secara harfiah berarti hubungan antar jaringan komputer (network). Sedangkan network sendiri diartikan sebagai suatu sistem komunikasi data antar komputer. Contoh jaringan komputer yang paling sering kita temukan misalnya Local Area Network (LAN) yang menghubungkan komputer-komputer yang berada dalam suatu areal atau lokasi tertentu seperti kantor, sekolah, perusahaan, warnet dan lain-lain. (http://id.wikipedia.org/wiki/Internet, 2014)

\subsubsection{Kegunaan Internet}

Banyak kegunaan yang menguntungkan yang didapatkan dari penggunaan internet dalam semua bidang (bisnis, akademis, pemerintahan, organisasi dan lain sebagainya), antara lain:

1. Informasi yang didapatkan lebih cepat dan murah, yaitu dengan penggunaan aplikasi yang mendukung dan memadai.

2. Mengurangi biaya distribusi dan kertas, contoh : koran masuk, brosur, dan majalah

3. Sebagai media promosi penjualan online, contoh:
a. Image Company
b. Pengenalan dan pemesanan produk

4. Komunikasi Interaktif:
a. Email
b. Dukungan pelanggan dengan feed back

\subsection{PHP}

PHP: Hypertext Preprocessor adalah bahasa skrip yang dapat ditanamkan atau disisipkan ke dalam HTML.(Raharjo, Heryanto dkk,2010). PHP adalah bahasa pemrograman server side yang sudah banyak digunakan pada saat ini, terutama untuk pembuatan website dinamis. Untuk hal-hal tertentu dalam pembuatan web, bahasa pemrograman PHP memang diperlukan, misalnya saja untuk memproses data yang dikirimkan oleh pengunjung web.

\subsubsection{Kelebihan PHP}

Beberapa kelebihan PHP dari bahasa pemrograman web, antara lain:

1. Bahasa pemrograman PHP adalah sebuah bahasa script yang tidak melakukan sebuah kompilasi dalam penggunaanya.

2. Web Server yang mendukung PHP dapat ditemukan dimana - mana dari mulai apache, IIS, Lighttpd, hingga Xitami dengan konfigurasi yang relatif mudah.

3. Dalam sisi pengembangan lebih mudah, karena banyaknya milis - milis dan developer yang siap membantu dalam pengembangan.

4. Dalam sisi pemahamanan, PHP adalah bahasa scripting yang paling mudah karena memiliki referensi yang banyak.

5. PHP adalah bahasa open source yang dapat digunakan di berbagai mesin (Linux, Unix, Macintosh, Windows) dan dapat dijalankan secara runtime melalui console serta juga dapat menjalankan perintahperintah sistem. 


\subsection{E-Learning}

Menurut "E-learning adalah metode pembelajaran baru berupa perpaduan antara teknologi jaringan dan multimedia yang dikawinkan dengan pedagogi dan andragogi. E-learning merupakan dasar dan konsekuensi logis dari perkembangan teknologi informasi dan komunikasi. ( Ariesto Hadi Sutopo, 2012). Pembelajaran, penyampaian materi, diskusi, dan lain-lain dilakukan melalui media elektronik. Dengan e-learning, siswa tidak datang di ruang kelas untuk bertemu dengan guru secara langsung dalam proses pembelajaran. E-learning juga dapat mempersiapkan waktu pembelajaran, menghemat biaya yang harus dikeluarkan oleh program pendidikan. E-learning yang dikembangkan berbasiskan web sering disebut dengan Internet Enabled Learning."

\subsection{Perancangan Sistem}

Perancangan atau yang sering kita sebut dengan rancangan sistem merupakan salah satu unsur atau tahapan dari keseluruhan pembangunan sistem komputerisasi. Salah satu unsur pokok yang harus dipertimbangkan dalam pembangunan sistem komputerisasi yaitu masalah perangkat lunak, karena perangkat lunak yang digunakan haruslah sesuai dengan masalah yang akan diselesaikan, disamping masalah perangkat keras itu sendiri. Perancangan sistem terdiri dari 2 (tahap), yaitu :

1. Tahap Studi

Tahap studi meliputi 3 (tiga) tahap, yaitu :

a. Identifikasi, dalam tahap ini harus didapatkan uraian yang jela mengenai tujuan dari pada system.

b. Dokumentasi, dalam tahap ini ditentukan file-file dan dokumen laporan apa saja yang diperlukan untuk mencapai tujuan yang diinginkan.

c. Evaluasi, tahap ini mengevaluasi semua kemungkinan alternative yang ada dan kemudian memilih yang paling fleksibel.

2. Tahap Operasi

Tahap ini mempunyai tahap-tahap lagi, yaitu :

a. Perancangan, hal yang dilakukan di sini adalah membuat spesifikasi secara terinci dari sistem yang baru.

b. Instalasi, langkah ini adalah merupakan implementasi dari sistem yang baru.

c. Testing, pada langkah ini dipastikan apakah sistem yang diajukan benar-benar dapat menghasilkan tujuan dengan lebih efisien.

\subsection{Sistem Informasi}

Menurut Ariesto Hadi Sutopo, (2012): "Sistem informasi terdiri dari dua kata yaitu "sistem" dan "informasi". Sistem sendiri berarti gabungan dari beberapa komponen yang bekerja sama untuk mencapai satu tujuan. Informasi berarti sesuatu yang mudah dipahami oleh di penerima. Sistem informasi memiliki makna sistem yang bertujuan menampilkan informasi.

\subsection{Browser}

Browser atau yang lebih dikenal dengan sebutan web browser merupakan sebuah program aplikasi yang digunakan untuk menjelajahi dunia maya (Internet). Aplikasi ini mempunyai kemampuan menampilkan suatu web page yang ditulis dalam bentuk dokumen HTML.

\subsection{Basis Data (Database)}

Menurut Ariesto Hadi Sutopo (2012) "Basis data (database) adalah kumpulan informasi yang disimpan di dalam computer secara sistematik sehingga dapat diperiksa menggunakan suatu program komputer untuk memperoleh informasi dari basis data tersebut (Silberscatz, 1998). Perangkat lunak yang digunakan untuk mengelola basis data disebut system manajemen basis data (Database Management Sistem $=$ DBMS).

$A d$ a beberapa pengertian basis data, yaitu :

1. Himpunan Kelompok Data (Arsip) yang saling berhubungan dan diorganisasikan sedemikian rupa agar kelak dapat dimanfaatkan kembali dengan cepat dan mudah.

2. Kumpulan data yang saling berhubungan yang disimpan secara bersama sedemikian rupa dan tanpa pengulangan (Redundensi) yang tidak perlu.

3. Kumpulan File/Table/Arsip yang saling berhubungan yang disimpan dalam media penyimpan Elektronik.

\subsection{MySQL}

MySQL adalah Relational Database Management System (RDBMS) yang didistribusikan secara gratis dibawah lisensi GPL (General Public License). Dimana setiap orang bebas untuk menggunakannya, tapi tidak boleh dijadikan produk turunan yang bersifat Closed Source atau komersial. (Raharjo, Heryanto dkk,(2010)

MySQL sebenarnya merupakan turunan salah satu konsep utama dalam database sejak lama, yaitu SQL (Structur Query Language). SQL adalah sebuah konsep pengoperasian database, terutama untuk pemilihan atau seleksi dan pemasukan data, yang memungkinkan pengoperasian data dikerjakan dengan mudah secara otomatis.

Sebagai database server, MySQL dapat dikatakan lebih unggul dibanding database server lainnya dalam query data. Hal ini terbykti untuk query yang dilakukan oleh single user, kecepatan query MySQL bisa sepuluh kali lipat lebih cepat dari PostgreSQL dan Lima kali lebih cepat dibanding Interbase. 


\subsubsection{Keistimewaan MySQL}

Sebagai database server yang memiliki konsep database modern, MySQL memiliki banyak keistimewaan. Berikut ini beberapa keistimewaan yang dimiliki oleh MySQL.

1. Portability

MySQL dapat berjalan stabil pada berbagai system operasi seperti Windows, Linux, FreeBSD, Mac OS X Server, dan lain-lain.

2. Open Source

MySQL didistribusikan secara Open Source, sehingga dapat digunakan secara bebas.

3. Multi-user

MySQL dapat digunakan oleh beberapa user dalam waktu yang bersamaan tanpa mengalami masalah. Hal ini memungkinkan sebuah database server MySQL dapat diakses client secara bersamaan.

4. Performance Tuning

MySQL memiliki kecepatan yang tinggi dalam menangani query, dengan kata lain dapat memproses lebih banyak SQL per satuan waktu.

\subsection{CMS Schoolhos}

CMS Schoolhos merupakan sebuah sistem informasi sederhana yang dibangun dengan menggunakan bahasa permograman $P H P$ dan MySQL. Sistem ini adalah salah satu alternatif untuk membangun sebuah website informasi pendidikan atau instansi sekolah. Dalam CMS Schoolhos juga tersedianya Modul yang merupakan standar modul yang dibutuhkan oleh sebuah website sekolah pada umumnya, yaitu data siswa, data guru dan staff, data alumni, pendaftaran siswa baru dan materi untuk E-learning.

\section{ANALISA DAN PERANCANGAN \\ 2.3 Deskriptif Sistem}

Deskripsi Sistem menjelaskan tentang kondisi objek penelitian. pengidentifikasian masalah dalam penelitian adalah sistem informasi akademik yang akan diterapkan dalam Perguruan Islam Modern Amanah. Sehingga informasi yang ada pada sekolah dapat diterima oleh para siswa, pegawai dan masyarakat melalui website yang dirancang.

Peneliti memperoleh beberapa data yang dibutuhkan untuk kemudian dilakukan penyesuaian dengan sistem informasi yang telah dirancang. Data- data tersebut meliputin:

\section{Data Primer}

Yaitu data tentang akademik sekolah, antara lain

a. Data Seluruh Siswa-siswi SD dan SMP Plus Amanah.

b. Data Seluruh Staff Pegawai dan Guru SD dan SMP Plus Amanah

c. Foto-foto Sekolah dan kegiatan Siswa-siswi SD dan SMP Plus Amanah d. Materi-materi Pembelajaran SD dan SMP Plus Amanah

e. Profil Sekolah, termasuk: Sejarah, Visi, Misi dan strategi, Struktur Organisasi

\section{Data Sekunder}

Seperti: buku-buku, literature, laporan-laporan dan catatan-catatan. Data sekunder ini diperlukan sebagai tambahan data yang bersifat teoritis.

\section{Tahap Identifikasi}

Tahap dalam pengidentifikasian yang peneliti lakukan yaitu:

1. Lingkup Sistem

2. Analisis Sistem

3. Langkah-langkah Perancangan Sistem

4. Tinjauan Sistem yang Sedang Berjalan

3.1 Lingkup Sistem

Adapun Lingkup sistem yang dirancang dalam perancangan web akademik pada Perguruan Islam Modern Amanah meliputin:

1. Home
a. E-Learning
b. Sambutan Kepala Sekolah
c. Link

2. About
a. Sejarah
b. Visi, Misi dan Strategi
c. Keunggulan
d. Struktur Organisasi
e. Ekstrakulikuler
f. Lokasi Sekolah

3. News

4. Information
a. Agenda Sekolah
b. Pengumuman

5. School Community
a. Teacher
b. Staff
c. Students
d. Alumni

6. Gallery

7. Guest Book

8. PSB Online (Pendaftaran Siswa Baru)

\subsection{Analisis Sistem}

Terdapat langkah-langkah didalam melakukan analisis Sistem, diantaranya adalah :

1. Identify, yaitu mengidentifikasi masalah.

2. Understand, yaitu memahami kerja dari sistem yang ada.

3. Analize, yaitu menganalisis sistem

4. Report, yaitu membuat laporan hasil analisis.

\subsection{Langkah- langkah Perancangan Sistem}

ada beberapa langkah-langkah yang harus dilalui yang tidak terlepas dari SDLC (System Development Life Cycle) yaitu daur hidup sistem yang saling berkaitan, diantaranya : 
1. Permulaan

Survey pendahuluan.

2. Studi Kelayakan

a. Prosedur yang ada.

b. Perkiraan biaya.

3. Analisis Sistem

Perincian Prosedur yang ada.

4. Persyaratan Analisis
a. Kebutuhan pemakai.
b. Pengumpulan data, input, output.
c. Penetapan garis batas sistem (pembatasan maslah).

5. Perancangan Sistem
a. Perancangan sistem tanpa kendala.
b. Revisi pembuat yang ideal yang dapat diterima.

6. Spesifikasi Perancangan
a. Perancangan global.
b. Input/Output.
c. Perancangan file.
d. Pemprograman.
e. Syarat-syarat program
f. Petunjuk kerja.
g. Pemilihan bahasa pemprograman yang tepat.

7. Pengujian (Testing)
a. pengujian unit (Unit test).
b. Pengujian modul gabungan (Combined module test).

8. Konversi dan Pengawasan (implentasi)

9. Operasional
a. Pemeliharaan (Maintenance).
b. Evaluasi.

\subsection{Metode Perancangan \\ 3.4.1 Data Flow Diagram}

Menurut Tata Sutabri, (2012) "Pendekatan analisis terstruktur diperkenalkan oleh DeMarco(1978) dan Gane Sarson (1979) melalui buku metodologi struktur analisis dan desain system informasi. Adapun pengertian secara umum dari data flow diagram ini adalah suatu network yang menggambarkan suatu sistem automata / komputerisasi, manualisasi, atau gabungan dari keduanya, yang penggambarannya disusun dalam bentuk kumpulan komponen sistem yang saling berhubungan sesuai dengan aturan mainnya. Dalam hal ini penulis mengajukan Data Flow Diagram (DFD) sebagai berikut:

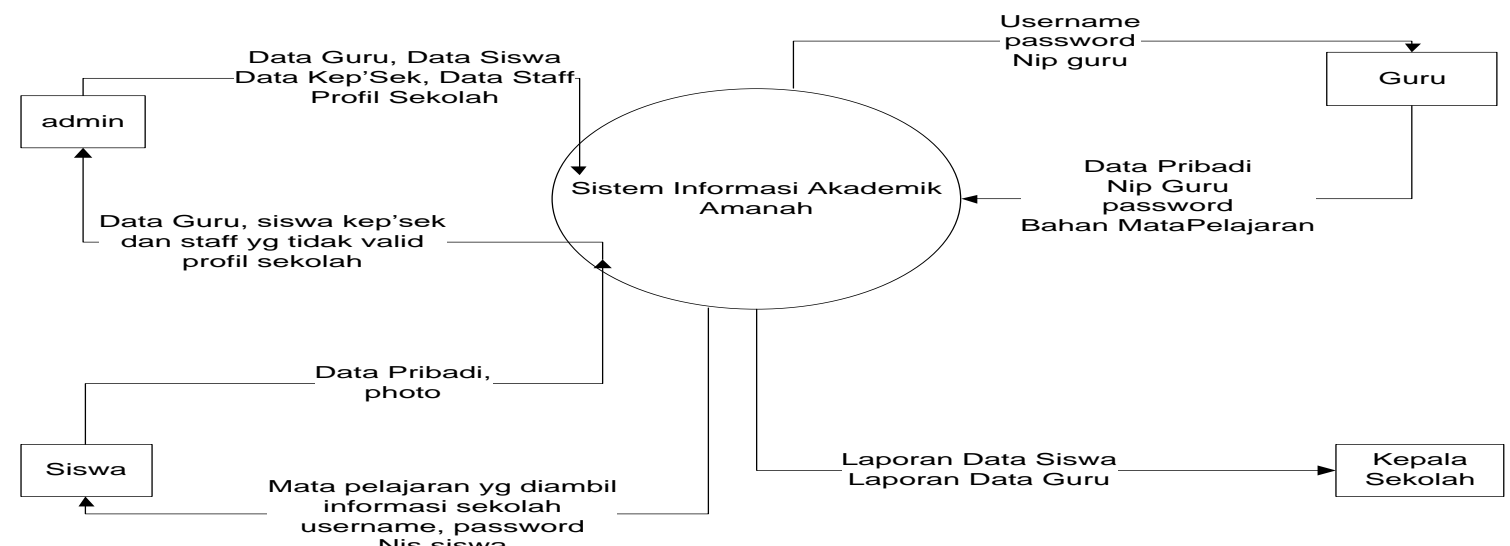

Gambar 3.1. Data Flow Diaaram Level Nol

\subsection{2}

\section{Perancangan Input Sistem}

Dalam pembuatan web ini dibutuhkan rancangan database. Database yang dirancang memiliki 21table dan dirancang menggunakan My SQ1.

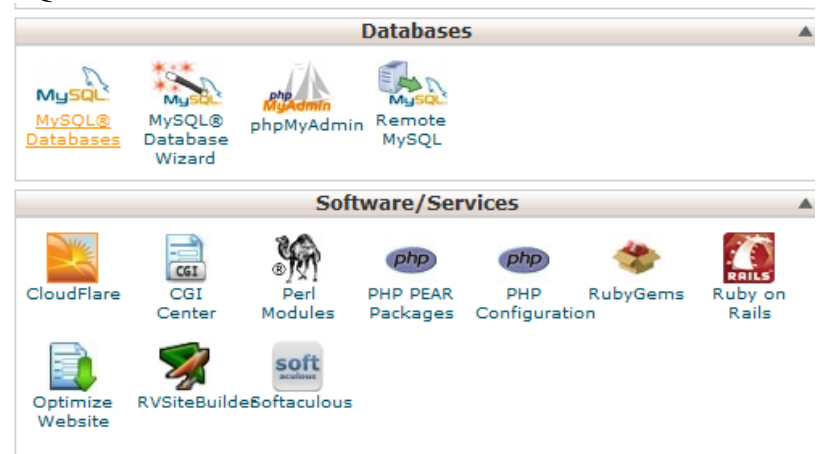

Gambar 3.3 Database Mysql

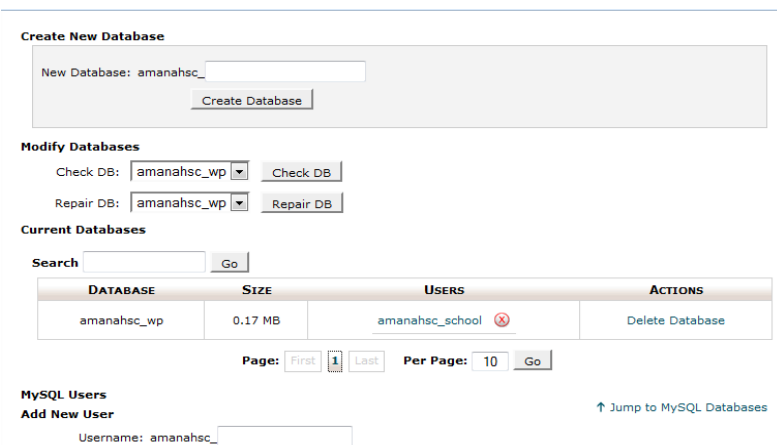

Gambar 3.4 Database sekolah 
Tabel-tabel yang ada diantaranya :

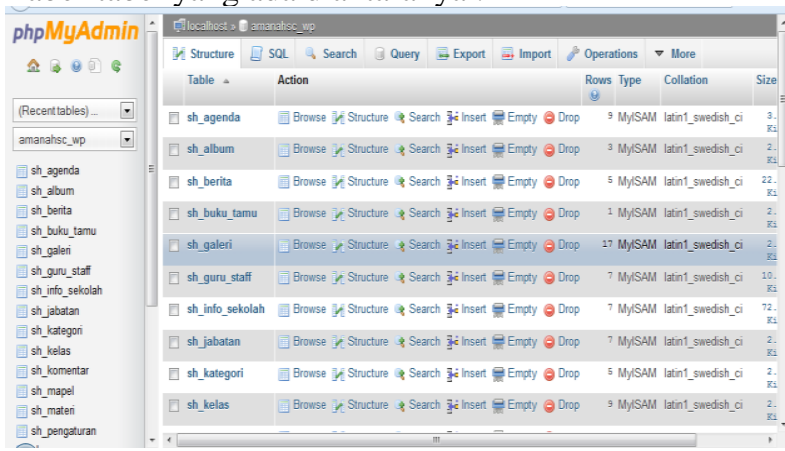

Gambar 3.8 Tabel- table database

table sh_agenda, sh_album, sh_berita, sh_buku_tamu, sh_galeri, sh-guru_staff, sh_info_sekolah, sh_jabatan, sh_kategori, sh_kelas, sh_komentar, sh_mapel, sh_materi, sh_pengaturan, sh_pengumuman,

\section{DAFTAR PUSTAKA}

1. Badan Pusat Statistik (BPS) Sumut. (2013). http://sumut.bps.go.id. Diakses oleh: Dewi Maharani.

2. Siap. (2013). http://medan.siap.web.id. Diakses oleh: Dewi Maharani

3. Wikipedia. (2013). Pengertian Internet.http://id.wikipedia.org/wiki/Internet. Diakses oleh : Dewi Maharani.

4. Wikipwedia. (2013). http://id.wikipedia.org/wiki/Adobe_Photoshop. Diakses oleh: Dewi Maharani.

5. Sutabri, Tata. (2012). Analisis Sistem Informasi. ANDI. Yogyakarta

6. Sofana, Iwan. (2008). Membangun Jaringan Komputer. Informatika. Bandung

7. Kusnaidi, dkk. (2008). Sistem Operasi. ANDI. Yogyakarta

8. Sutopo, Ariesto, Hadi.(2012). Teknologi Informasi dan Komunikasi dalam Pendidikan. Graha Ilmu. Yogyakarta

9. Zainal, A. (2007) Metodologi Penelitian Pada Bidang Ilmu Komputer Dan Teknologi Informasi. Bumiaksara. Depok.

10. Cholid Narbuko dan Abu Achmadi. (2006) Metodologi Penelitian. Bumiaksara. Jakarta. Irawan. (2008). Pengenalan Komputer. Maxikom. Palembang. 